\title{
The Exploration and Practice for Project Teaching Method
}

\author{
Hailan $\mathrm{Pan}^{1, \mathrm{a}}$, Chen Jian ${ }^{1, \mathrm{~b}}$ and Cuihong $\mathrm{Wu}^{1, \mathrm{c}}$ \\ ${ }^{1}$ School of Economics and Management, Shanghai Second Polytechnic University, \\ 2360Hao, JinHaiLu, PuDong Shanghai 201209 China

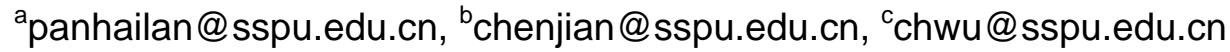

\begin{abstract}
Keywords: Project teaching method; System analysis and design; E-commerce projects;
\end{abstract} implementation; evaluation

\begin{abstract}
Project teaching method is a kind of teaching method around the project, which let the students put the classroom knowledge into projects in the form of learning team, and improve the students' professional knowledge and skills through practice. This paper introduces the concept and characteristics of project teaching method, and then through teaching and practicing of the course "Systems analysis and design method of E-commerce", analyzes several aspects about the project definition, project design and planning, project implementation, project evaluation and demonstration, and especially shares special problems and solving methods In the process of curriculum implementation to provide reference for the future.
\end{abstract}

\section{Introduction}

After more than 2 years of the key course construction of shanghai second polytechnic university, "Systems analysis and design method of E-commerce" get excellent evaluation in project review under the joint efforts of many teachers and classmates. During curriculum reform the traditional subject curriculum pattern was changed, the team project practice was selected to drive teaching and meet different levels of students needs in order to stimulate students' potential in the teaching process, which used students' team to supervise and promote learning, and obtained the widespread high praise of the students. The exploration and practice of project teaching method in our course construction team will have a certain degree of reference significance to other similar courses.

\section{The Concept and Characteristics of Project Teaching Method}

Project teaching method is a kind of typical of student-centered teaching method, which is driven with project and teachers' participation in instruction to train students' teamwork ability, autonomous learning ability and innovation exploration ability, so as to let the students passively listening to active learning. Project teaching method has changed the traditional teaching mode of "teacher taught, students listen" phenomenon, but by curriculum design including all the knowledge, students' teams was ordered to finish a complete project, and the teacher as a guide and supervision coordinator in the process of project completion to ensure the smooth progress of the project [1-2].

\section{The Exploration and Practice of Project Teaching Method in the Course}

The curriculum of "systems analysis and design method of E-commerce" has begun the course construction from the end of 2012, and many people were involved in curriculum design, research and teaching process, including students of E-commerce professional from Grade 11 and Grade 12, four teachers and an enterprise project manager. In the process of more than two years of educational reform, we have accumulated some experience for the construction of this course, and will set forth several aspects about the project definition, project design and planning, project implementation, evaluation and display in the following paper.

Project definition In project teaching method the team project has always been throughout the course, so the choice and definition of project will play a decisive role for the whole project process. 
The curriculum goal of "systems analysis and design method of E-commerce" was to make students understand and master the involved knowledge to build the E-commerce system, and master the basic concept and principle of system analysis and design, and is proficient in the system development life cycle process, especially the phase of system analysis and system design, and learn to use the Rational Rose tool to carry out related UML diagram. Therefore project in the course is derived from the previous graduation design, enterprise real projects, all kinds of E-commerce competitions and computer design competitions etc.

According to the above way teachers would provide at least 50 topics for student teams to choose, and these issues need to meet the feasibility and practicality, and conform to the latest social demands, also can solve practical e-commerce business activities and let students interested in.

Project design and planning In order to let students experience the integrity of the project process, we let the student team act as three characters: client, developer and acceptor. That is students' team must select interested projects provided from teachers, and discuss to release the problems which this project needs to solve in the course website, and then let the other team to undertake the project so as to exercise the students' communicative competence and Understanding ability [3].

According to the course content the project was down into several projects node including requirements analysis, feasibility analysis, data modeling, process modeling, function analysis, software structure design, the input and output, and user interface design in the whole teaching process, and in order to supervise and restrain students' project schedule.

Project implementation In the process of project implementation, teachers are critical to the timely intervention guidance, otherwise it will lead to the phenomenon of project rework sharply increased, which affects the completion of the entire project. For this course, in order to make students easier to understand new knowledge, we selected a typical E-commerce site, "Qing Feng” online bookstore, as a teaching example, and reasonable allocation of project node and classroom teaching cohesion, and let the student finish project practice in a timely manner after the lectures. Teachers must not only explain the knowledge points, but also participate in some discussions and error correction when students complete the project node, and collect the common problems, and explain outstanding and common errors from students' team in classroom teaching, so as to allow students to inspect again their own work achievement, and improve the practical ability and understanding ability, and form a virtuous circle of theory to practice to theory.

Of course, the student team is most important for the implementation of the project, planning and leadership of the group leader are also very important, the second is the executive ability of the group members. So students must apply for team leader, and if a group leader is too little then the teacher can designate team leader but must help specify them in the beginning of a team, and let the students keep discuss data including images, audio or video can also help the team leader. Every team members need discuss the whole framework together in the process of project implementation, and the team leader should reasonably divide the work about analysis and design of each function point and timely adjust workload of members according to the actual completion schedule to exercise and improve their self-study ability, practice ability, innovation ability and the team cooperation ability [4].

Project evaluation and display After finishing the whole project, students must show results for teacher and the other teams by a variety of ways such as making open reply and reviewing project etc. At the same time project output can also be uploaded to the network to be reference for other project team and the future study of students.

Before the last class at the end of the semester, teachers will organize project review and each project review process including:

Step1: customer representative on project requirements;

Step2: any student in developer use PPT to report analysis report;

Step3: the other student in developer use PPT to report design report;

Step4: client, acceptor and teachers question and comment;

Step5: representatives for all teams grade for the project to improve the students' participation. 
Finally we will reward points for the top three of all team members on their final course grade by comprehensive sequencing. These measures improve the students' participation to a certain extent, and their report results are also more excellent.

\section{The Problem and Solution of Implementation of Project Teaching Method}

Through practice of two teaching class, we found that the project teaching method needs to solve many unexpected problems in the process of the project and needs the teacher accumulate experience to continuous improvement, while traditional way of teaching only planned good content of course. The following share our problems and solutions in the process of implementation.

A team problem During the educational reform practice of Grand 11, in order to centralized plan and guide, we let the student form a team eight to ten, and ask the students to a specified group, so lead to a series of problems such as the team members are too much, less communications between members because they are not familiar, and all these are a big challenge for the team leader, some groups emerge the phenomenon that only team leader and individual students are involved in the project in the end. According to these, during the educational reform practice of Grand 12, we let the student freedom form a team four to five. Although the teachers' workload multiplied, the few number of student member make high efficiency to complete the project by a two-way choice.

For the phenomenon of no team members willing to be group leader, we increased the regulation that the final grade of the group is grade of the group leader, the scores of members must be multiplied by the coefficient of group grade, so that students will be attracted to assume leadership. For those who can't be set to the team, teachers must help to communicate and coordinate.

Selection problem of topic During the educational reform practice of Grand 11, in order to exercise the students' ability to discover problems, student was asked for defining project topic by themselves and teachers conducted these topics. But it appeared a series of problems such as vague project demand and excess demand and leaded to the back of the project analysis and design is too difficult to be completed. According to these, during the educational reform practice of Grand 12, the teacher' team provided more than 50 project's topics for students which is selected form the case company, college's competition and previous graduation project, and gave students a range of topics, so as to expand the students' awareness of the selected project topic and avoid infeasible projects.

Scale of project requirement During the educational reform practice of Grand 11, teachers' requirements to each node project were more general, which leaded to the workload for each team is very uneven, and single from the entity relationship analysis is the difference between 5 to 10 entities. Therefore in the teaching of grade 12 in order to reduce the phenomenon of radio actior, in the project task node, the projects' specifications were required to be quantitative close to the team number, which ensured that everyone can complete the project node involved in knowledge because the project content were not too big.

Project review During the educational reform practice of Grand 11, in order to improve the students' individual ability and the team leaders' rights, team performance evaluation was divided three parts including individual self-evaluation, group leader and the teachers, and their proportion is 3:3:4 respectively. But during the implementation of project we found that the students' self-evaluation is unfair, and some leaders were unified score in order not to upset people. All these not only hit the enthusiasm of the students but also caused trouble to teacher's comprehensive score. So in the teaching of grade 12 the team of teachers improved times for each group of communication, and changed the proportion to 1:2:7. Effect was improved markedly, and the students also had no objection, but the teachers' extracurricular work was improved.

The guidance of teachers During these two teaching practices, we found that teacher's request in the project teaching method was too high, class is not completely enough and some essential links was necessary including timely intervention project process, timely problem solve and communication with team for many times. So we established the course website (http://cc.sspu.edu.cn/g2s/Template/View.aspx?action=view\&courseType=0\&courseId=29625), and solved problems arising from the team through the BBS, assignments and questions to communicate. 


\section{The Effect and Evaluation of the Implementation of Project Teaching Method}

Through two school year teaching practice, the curriculum goal of "systems analysis and design method of E-commerce" improves educational effect, students' learning enthusiasm and initiative has a certain degree of increase, but also from the knowledge understanding, horizons, team work and engineering practice ability, etc. have been progress, of course, teachers' practical ability and teaching level is also improved[5-6].

(1) The students improve the ability of all aspects. From the project subject to the layers of implementation, students are required to active learning, comprehensive analysis and apply relevant knowledge of before and after the course, to achieve mastery each subproject through a comprehensive study, which inspired the students' subjective study and comprehensive analysis ability. At the same time, the implementation of the project needs to strengthen the communication between team members, coordinate with the demand side, and complete the survey, entity relationship, data flow diagram, software structure, interface design and documentation and so on engineering practice, and therefore improve the students' project practice ability and the team cooperation ability.

(2) To promote the construction of network resources and laboratory. the educational reform constructs the teaching website, currently it has more than ten thousand hits, which is divided into 10 columns, including course introduction, teaching documents, network teaching, experiment and practice, teaching video recording, software resources, achievements of the curriculum establishment, curriculum evaluation, teaching materials and interaction, the teachers make full use of the interactive teaching process BBS to give students answers to questions in a timely manner. Practice also promotes the laboratory fully open at the same time, and makes the laboratory resources get effective utilization, so as to promote the construction of the laboratory.

(3) Students get extracurricular harvest. Through analysis and design of the project in the course, some teams will use extra-curricular time to complete the complete project involved in college students' innovative projects in Shanghai and all kinds of competition. During these two years team teacher led project approved six college students' innovative project, also achieved contest award such as competition in Shanghai university student contest of E-commerce, network business innovation application contest in Shanghai, Shanghai college students' computer application ability contest and Chinese college students computer design contest etc.

(4) Teachers improve engineering practical ability and teaching level. Project teaching method needs teachers with rich project experience, therefore the teaching process promoted the teacher team to research, collecting enterprise case and arrange, during this period teachers had completed three enterprise projects, two theses for teaching, one excellent teaching award, 1 experiment instruction, and collected eight large complete projects, multiple small projects, all these resources provide good resources for the future teaching.

After two years of teaching reform, our investigation shows that students' satisfaction on project teaching is $96.2 \%$, and students who agree with team approach is $98.23 \%$, and students also suggest for the future teaching including increase the team mutual links during project review, and case number is not enough etc., these are very valuable opinions in the construction of courses in the future.

\section{Conclusion}

For stronger practical course, especially for courses which knowledge related and forward-backward correlation, the project teaching method can fully arouse the enthusiasm of students, let students experience the fun of learning in practice. But many factors play a decisive role for the project teaching method including the form of the teaching design, the content of the project, the timeliness of under the guidance of teachers, the composition of the student team composition and the rationality of the scoring system and so on. Therefore team of teachers should plan before teaching, and timely adjust the schedule according to actual condition, after teaching should summarize and improve quickly, so as to apply the project teaching method well to finish a course. 


\section{Acknowledgements}

This work was financially supported by "Credit Management” discipline team building of Shanghai Second Polytechnic University (B50NH133104B) and undergraduate important course of municipal education commission in Shanghai in 2015.

\section{References}

[1] ShiHai Zhang. The exploration of implementation of project teaching method in marketing course[J]. Theory and Practice of Contemporary Education, Vol. 5 (2013), p. 124-125.

[2] HongBin Wang, LiuHua, LanRong Zhao etc. Teaching reform and practice of information literacy education curriculum oriented by project driven[J], Journal of the Library Science of Sichuan, Vol. 3 (2013), p. 68-70.

[3] zun-yue qin, Huang Yun, hong-zhi xu, etc. Java language teaching reform of software engineering based on the concept of CDIO[J], Computer Education, Vol. 19 (2012), p. 77-81.

[4] HaiJun Wang. the application of project teaching in computer teaching reform[J]. Information Systems Engineering, Vol. 7 (2012), p. 155-156.

[5] LiPing Cai, WangBiao Li, JinBiao etc., the CDIO digital circuit experiment teaching of software engineering design [J], Computer Education, Vol. 6 (2013), p. 17-20.

[6] NieHai, FengSong Wu, ZongShuai Yang etc. Management of combining student's creative project and open laboratory based on CDIO model [J], Experiment Science and Technology, Vol. 6 (2012), p. 170-173. 